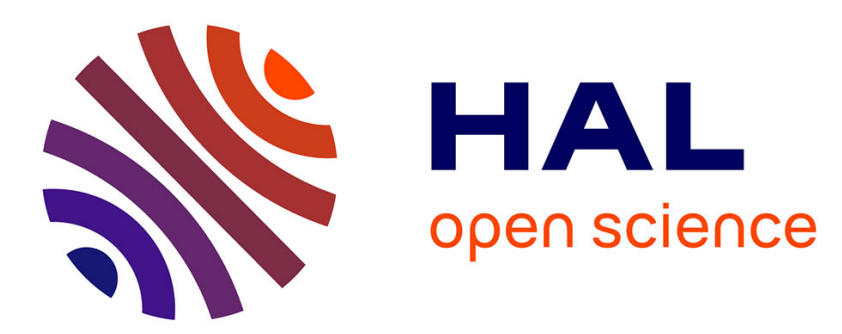

\title{
Numerical and experimental analysis of residual stress and plastic strain distributions in machined stainless steel
}

\author{
Naoufel Ben Moussa, Habib Sidhom, Chedly Braham
}

\section{To cite this version:}

Naoufel Ben Moussa, Habib Sidhom, Chedly Braham. Numerical and experimental analysis of residual stress and plastic strain distributions in machined stainless steel. International Journal of Mechanical Sciences, 2012, 64 (1), pp.82-93. 10.1016/j.ijmecsci.2012.07.011 . hal-02390617

\section{HAL Id: hal-02390617 https://hal.science/hal-02390617}

Submitted on 3 Dec 2019

HAL is a multi-disciplinary open access archive for the deposit and dissemination of scientific research documents, whether they are published or not. The documents may come from teaching and research institutions in France or abroad, or from public or private research centers.
L'archive ouverte pluridisciplinaire HAL, est destinée au dépôt et à la diffusion de documents scientifiques de niveau recherche, publiés ou non, émanant des établissements d'enseignement et de recherche français ou étrangers, des laboratoires publics ou privés. 


\title{
Numerical and experimental analysis of residual stress and plastic strain distributions in machined stainless steel
}

\author{
N. Ben Moussa ${ }^{a}$, H. Sidhom ${ }^{a, *}$, C. Braham ${ }^{b}$ \\ ${ }^{a}$ Mechanical, Material and Processes Laboratory (LR99ES05), ESSTT, 5, Avenue Taha Hussein 1008, University of Tunis, Tunis, Tunisia \\ ${ }^{\mathrm{b}}$ Laboratoire de Procédés et Ingénierie en Mécanique et Matériaux (PIMM, UMR CNRS 8006), Arts et Métiers-ParisTech, 151, Boulevard de l'Hôpital Paris, \\ 75013, France
}

\section{A R T I C L E I N F O}

Keywords:

Numerical simulation

Residual stress

Plastic strain

Machining

Surface properties

\begin{abstract}
A B S T R A C T
In this study, a numerical approach has been developed to predict the near surface residual stresses and plastic strain resulting from turning in orthogonal cutting configuration. This approach is based on the Arbitrary Lagrangian-Eulerian (ALE) formulation using the commercial finite element code AbaqusExplicit. The coefficients of the used material behavior law and friction model required for the simulation are identified experimentally in this study. The simulated results are validated by experiments carried out on AISI 316L stainless steel. Using this method, the effect of the depth of cut $(D o c)$ and the cutting speed $(V c)$ on the surface properties has been established. The simulated residual stress gradient resulting from machining has been experimentally validated by X-ray diffraction measurements. The simulated plastic strain gradient has been validated by an experimental microhardness-strain relationship established in this study.
\end{abstract}

\section{Introduction}

The tool-material interactions under machining conditions appreciably modify the properties of near surface layers of metal and subsequently their behavior and durability. The nature and the extent of the modifications depend on the types of toolworkpiece interactions. The identification of these modifications is extremely useful for a better prediction of the in-service life time of machined components subject to cyclic loading or stress corrosion cracking. For a long time, the identification of the properties of the near surface layers affected by machining was based on experimental approaches combining various techniques and methods of mechanical and physicochemical investigations [1]. These approaches are expensive and lead to more or less significant uncertainties of surface properties. For this reason, analytical approaches, based generally on geometrical considerations, have been developed. These approaches have recognized continuous development since the beginning of the previous century [2]. Nevertheless, the developed analytical models were mainly used to predict machining power or tool life by estimation of cutting forces and generated heat and are rarely used to predict the properties of machined surface. This is attributed to the large number of the involved and coupled physical phenomena as

\footnotetext{
* Corresponding author. Tel.: +216 71496 066; fax: +21671 391166.
}

E-mail address: habib.sidhom@gmail.com (H. Sidhom). contact mechanics, thermal transfer, metallurgical transformations, dynamics of machining, etc.

The numerical approaches found successful applications in recent years. Three different approaches were commonly used to simulate metal cutting: Lagrangian, Eulerian and Arbitrary Lagrangian-Eulerian. The main advantages of each formulation are summarized in Table 1.

However, the numerical investigations were focused commonly on cutting forces and chip morphology prediction [3,4].

The Lagrangian formulation has been used in several works to investigate the effect of machining parameters on residual stresses distribution. These works focused commonly on analyzing the effect of cutting speed [5-10], depth of cut [6,8,10-12], number of passes $[8,13,14]$ and cutting tool geometry and coating $[8,15-20]$. Nevertheless, the drawbacks of Lagrangian models cited in Table 1 reduce the profitability of these models.

Despite the advantages of the ALE formulation, its use in metal cutting simulation was very limited. Nasr [21] and Munoz [22] have presented an ALE finite element model to simulate the residual stresses induced by orthogonal dry cutting of the austenitic stainless steel AISI 316L. The works were limited to the study of the effect of tool edge radius on machining residual stresses.

Examination of the main numerical investigations of material cutting process can lead to the following comments:

- The numerical simulation results are very sensitive to the used material behavior laws [23], friction model [13,17,24] and mesh smoothness $[14,21]$. 
Table 1

Comparison between different formulations used in metal cutting simulation.

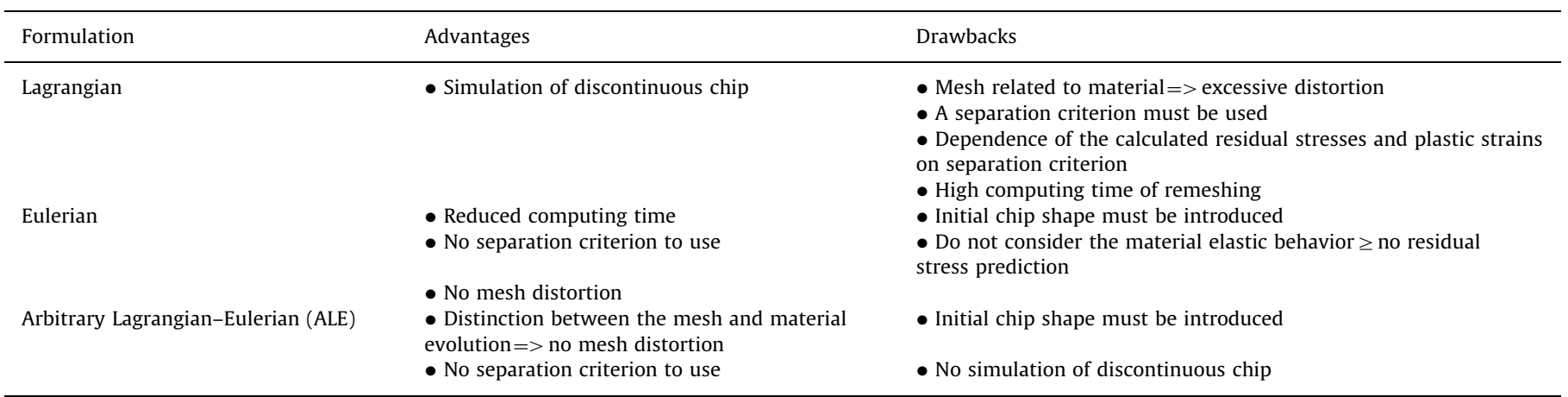

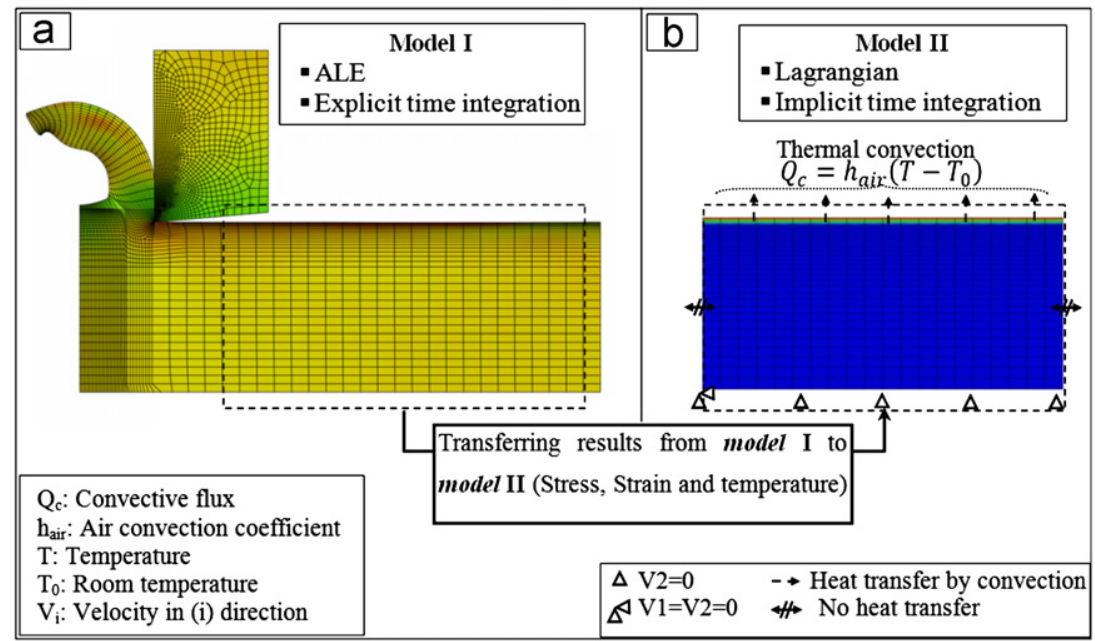

Fig. 1. Numerical simulation description.

- The explicit integration scheme is more efficient for applications involving high nonlinearities such as metal cutting simulation $[21,22]$.

- The machining residual stress is very sensitive to the friction condition of the tool-chip interface. Nevertheless, the coulomb model with a constant coefficient was usually used to describe friction in metal cutting simulation $[8,14,16,17,25]$.

- The simulated machining residual stress distributions are characterized by high tensile value near the surface in both directions (circumferential and axial) for austenitic stainless steels $[8,11,19-22]$. Moreover, in cutting direction (circumferential) the tensile residual stress is higher. In all cases, their levels are mainly controlled by the selected machining parameters which affect the generated heat flux.

- The simulated machining residual stresses are rarely validated by experimental measurements for different cutting conditions. The models validations are usually based on cutting forces measurements $[7,13,20]$.

- The simulated residual stresses were never been confirmed by an assessment of plastic deformation fields which is the bases of their generation.

For these reasons, we propose, in this study, a numerical approach to predict the surface residual stress and strain gradients resulting from cutting material process. This approach is based on the ALE formulation using the commercial finite element code Abaqus-Explicit and pre-defined experimental material behavior laws and friction models. The finite element model is calibrated by residual stresses and plastic strains measured on AISI 316L stainless steel samples machined in different cutting conditions. The effects of cutting condition on surface residual stress and strain distribution are investigated.

\section{Numerical approach}

\subsection{Numerical simulation procedure}

The approach adopted to predict the near surface residual stresses and strains induced by turning consists of reproducing the generation mechanisms of residual stress and strain in metal cutting by simulating separately:

- The phase of tool/material interaction, in a kinematic of cut, that consists of simulating the viscoplastic flow of the material on the tool cutting face (model I Fig. 1(a)).

- The phase of unloading and cooling of the workpiece until reaching mechanical equilibrium and room temperature in the workpiece (model II Fig. 1(b)).

In this procedure, the friction coefficient and material behavior law are provided from experimental data (Fig. 2).

\subsubsection{Simulation of tool/material interaction (model I)}

In a first step, an ALE model is used to simulate the viscoplastic flow of the material at the tool cutting face that is considered as fixed. 


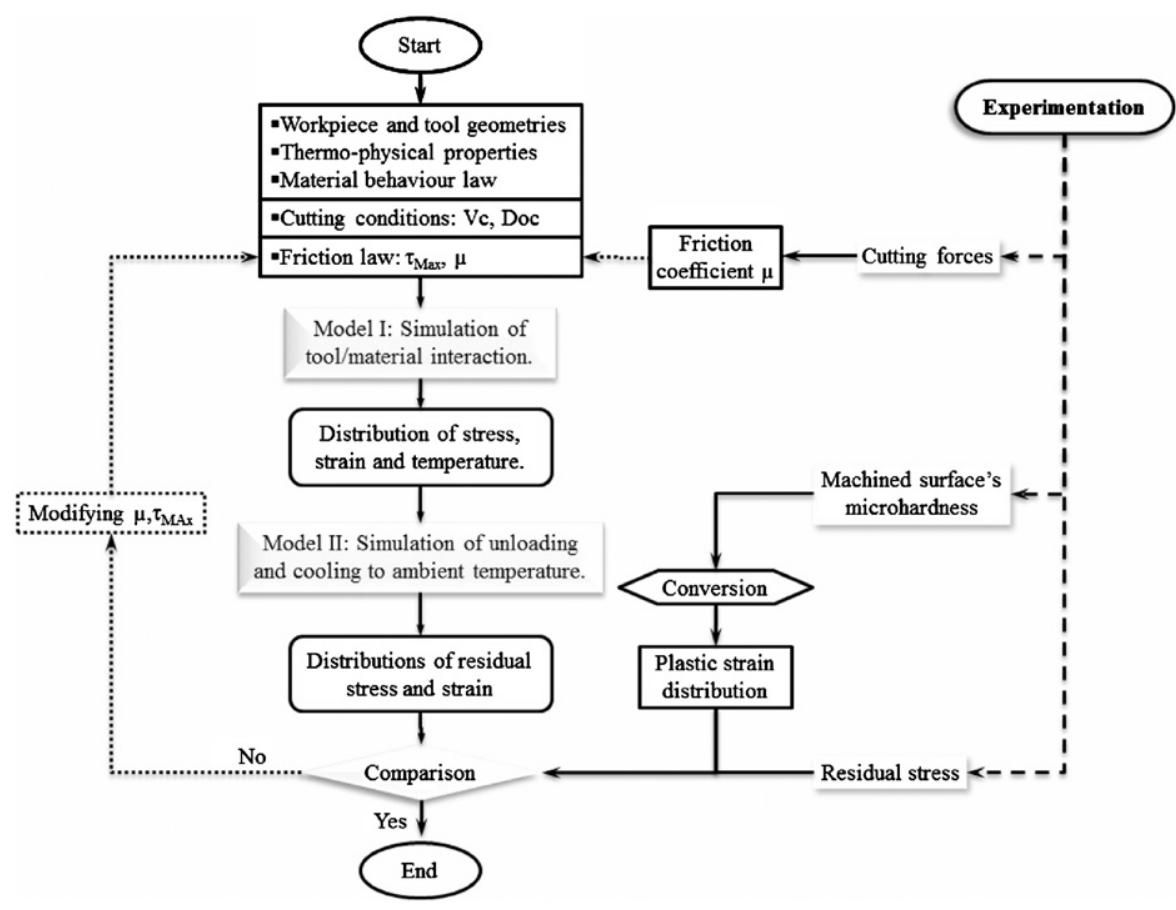

Fig. 2. Methodology used to predict machining residual stress and plastic strain by FE method.

Table 2

Chemical composition.

\begin{tabular}{lllllllllll}
\hline $\mathrm{C}$ & $\mathrm{Si}$ & $\mathrm{Mn}$ & $\mathrm{P}$ & $\mathrm{S}$ & $\mathrm{N}$ & $\mathrm{Cr}$ & $\mathrm{Mo}$ & $\mathrm{Ni}$ & $\mathrm{Cu}$ & $\mathrm{Co}$ \\
\hline 0.018 & 0.38 & 1.84 & 0.035 & 0.029 & 0.078 & 16.6 & 2.02 & 10.2 & 0.36 & 0.18 \\
\hline
\end{tabular}

2.1.1.1. Material behavior law. The material used in this study is the austenitic stainless steel AISI 316L. The chemical composition and thermo-mechanical properties of this material are summarized in Table 2 and Table 3, respectively. The AISI 316L thermomechanical properties are introduced in the finite element code as function of temperature to describe the material behavior.

The constitutive law proposed by Johnson and Cook [26], available in ABAQUS/Explicit, provides a good description of material behavior subjected to large strains, high strain-rates and thermal softening. This law, described by Eq. (1), is used in the simulation proposed in this study. Table 4

$\sigma=\left(A+B(\bar{\varepsilon})^{n}\right)\left(1+C \ln \dot{\bar{\varepsilon}}^{*}\right)\left(1-\left(T^{*}\right)^{m}\right)$

where: $\dot{\bar{\varepsilon}}^{*}=\dot{\bar{\varepsilon}} / \dot{\varepsilon}_{0}$ and $T^{*}=T-T_{0} / T_{m}-T_{0}$

In Eq. (1), $\sigma$ is the material flow stress, $\bar{\varepsilon}$ is the equivalent plastic strain, $\dot{\varepsilon}_{0}=10^{-3}$ is the reference plastic strain rate, $\overline{\bar{\varepsilon}}$ is the plastic strain rate, $T_{m}$ and $T_{0}$ are the melting and the room temperatures, respectively. Tensile tests at different temperatures and strain rates were conducted on the studied stainless steel. The coefficients $(A, B, C, n$ and $m$ ), listed in Table 5 , are obtained from tensile curves using a fitting program. The difference between the material behavior law coefficients obtained in this work and those given by M'Saoubi [27] can be explained by the difference in cold work hardening associated with the initial material manufacturing process.

2.1.1.2. Conservation law. In ALE formulation conservation laws must be expressed considering the mesh motion throughout simulation. The relative velocity between material and mesh, called convective velocity $(c)$ is defined by $c=v-\hat{v}$ where $(v)$ and $(\hat{v})$ are the particle velocities in material domain and the mesh velocity, respectively.

As described by Donea et al. [28], the relation between the material time derivatives, the referential time derivatives and the spatial gradient given by Eq. (2), allows to establish the conservation laws in ALE description (Eqs. (3)-(5)) from those in pure Eulerian configuration. In Eqs. (3)-(5), $(\rho)$ is the mass density, $(\vec{f})$ is the body force, $(\sigma)$ is the Cauchy stress tensor, $(e)$ is the specific internal energy, $(D)$ is the strain rate tensor, $(r)$ is the body heat generation and $(\vec{q})$ is the heat flux vector.

$\left.\frac{\partial f}{\partial t}\right|_{X}=\left.\frac{\partial f}{\partial t}\right|_{X}+\frac{\partial f}{\partial x} \times c=\left.\frac{\partial f}{\partial t}\right|_{X}+c \nabla f$

Mass conservation $:\left.\frac{\partial \rho}{\partial t}\right|_{X}+\vec{c} \nabla \rho+\rho \operatorname{div} \vec{v}=0$

Momentum conservation : $\left.\rho \frac{\partial \vec{v}}{\partial t} \mid+\vec{c} \times \nabla \vec{v}\right)=\operatorname{div} \sigma+\vec{f}$

Energy conservation : $\rho\left(\left.\frac{\partial E}{\partial t}\right|_{x}+\vec{c} \times \nabla e\right)=\sigma: D-\operatorname{div} \vec{q}+r$

2.1.1.3. Geometries, mesh and boundary conditions. The workpiece and tool geometries as well as initial and boundary conditions are introduced into the model (Fig. 3). The workpiece and the tool were meshed with, respectively, 2804 and 1802 isoparametric quadrilateral elements (CPE4RT) available in Abaqus element library. The workpiece is defined in the model as an adaptive mesh domain where continuous remeshing is applied to reduce mesh distortion during simulation. A plane-strain coupled thermomechanical analysis was performed using orthogonal assumption. The mesh is extremely refined near the tool-workpiece and toolchip interfaces until a length of $10 \mu \mathrm{m}$ for the workpiece elements and $5 \mu \mathrm{m}$ for the tool's elements (Fig. 3). In the current model, workpiece is subdivided into four zones. Zones 1, 3 and 4 were 
Table 3

Mechanical and thermal properties of workpiece and tool-materials.

\begin{tabular}{lll}
\hline Property & AISI 316L [23] & Coated carbide insert [31] \\
\hline Mass density $\rho\left(\mathrm{kg} / \mathrm{m}^{3}\right)$ & $7921-0.614 T+2.10^{-4} T^{2}$ & 11,900 \\
Poisson ratio $v$ & 0.29 & 0.3 \\
Hardness $\mathrm{HV}_{50 \text { gf }}$ & 192 & 360.5 \\
Specific heat capacity $C_{p}(\mathrm{~J} / \mathrm{kg} \mathrm{K})$ & $440.79+0.58 T-10^{-3} T^{2}+7.10^{-7} T^{3}$ & 29.71 \\
Thermal conductivity $\lambda(\mathrm{W} / \mathrm{m} \mathrm{K})$ & $14.3+0.018 T-610^{-6} T^{2}$ & \\
Melting temperature $T_{m}\left({ }^{\circ} \mathrm{C}\right)$ & 1400 & \\
Thermal expansion $\alpha\left(\mu \mathrm{m} / \mathrm{mm}{ }^{\circ} \mathrm{C}\right)$ & 10.4 \\
Inelastic heat fraction $\beta$ & 0.9 \\
$T\left({ }^{\circ} \mathrm{C}\right)$ & Value & \\
\hline Young modulus $E(\mathrm{GPa})$ & \\
20 & 210.3 \\
150 & 191.7 \\
260 & 180 \\
350 & 191 \\
425 & 188.2 \\
480 & 186.2 \\
540 & 156.5 \\
1200 & 113.7 \\
\hline
\end{tabular}

Table 4

Coefficients of Johnson Cook law for the AISI $316 \mathrm{~L}$.

\begin{tabular}{|c|c|c|c|c|c|c|}
\hline$A(\mathrm{MPa})$ & $B(\mathrm{MPa})$ & $C$ & $n$ & $m$ & $\dot{\varepsilon}_{0}\left(\mathrm{~s}^{-1}\right)$ & Ref. \\
\hline $300 \pm 0.449$ & $1132 \pm 1.96$ & $0.051 \pm 0.001$ & $0.748 \pm 0.001$ & $1.286 \pm 0.009$ & 0.001 & Current work \\
\hline 301 & 1472 & 0.090 & 0.807 & 0.623 & 0.001 & {$[27]$} \\
\hline
\end{tabular}

Table 5

Measured cutting forces and friction coefficient for different cutting conditions.

\begin{tabular}{|c|c|c|c|c|c|c|c|c|c|}
\hline Condition & 1 & 2 & 3 & 4 & 5 & 6 & 7 & 8 & 9 \\
\hline Cutting speed $(\mathrm{m} / \mathrm{min})$ & 140 & 100 & 60 & 140 & 100 & 60 & 140 & 100 & 60 \\
\hline Depth of cut (mm) & 0.25 & 0.25 & 0.25 & 0.2 & 0.2 & 0.2 & 0.3 & 0.3 & 0.3 \\
\hline Cutting force $(\mathrm{N})$ & 192 & 320 & 320 & 135 & 250 & 250 & 190 & 437 & 360 \\
\hline Thrust force $(\mathrm{N})$ & 80 & 155 & 165 & 50 & 110 & 160 & 80 & 225 & 225 \\
\hline Friction coefficient $(\mu)$ & 0.42 & 0.48 & 0.51 & 0.37 & 0.44 & 0.64 & 0.42 & 0.51 & 0.62 \\
\hline
\end{tabular}

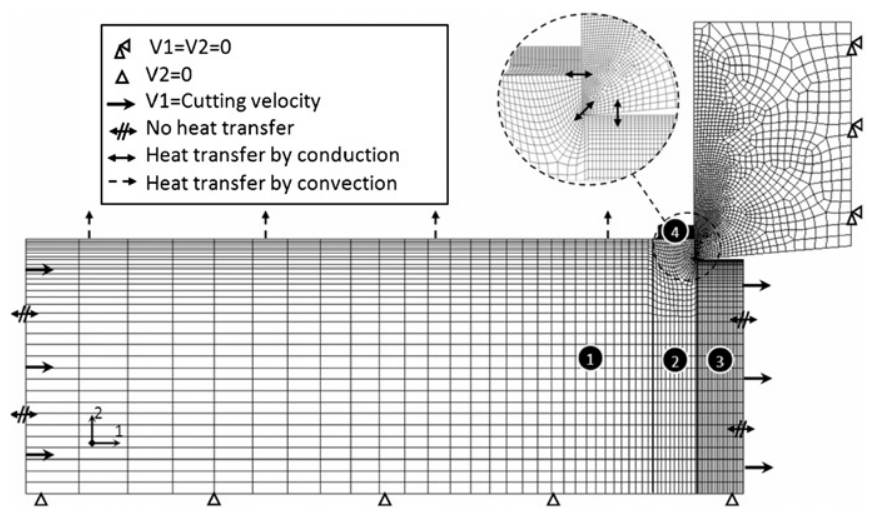

Fig. 3. Mesh, boundary and initial conditions of model I.

assumed as Lagrangian regions where the mesh is attached to the underlying material. This can be justified by the existing of free surfaces in these zones where the boundary conditions can be easily applied using Lagrangian description. The initial chip shape introduced in zone 4 is automatically updated along calculation to satisfy the thermo-mechanical equilibrium. The final shape and dimensions of chip depend on the evolution of thermal and mechanical loads independently from the first configuration. Nevertheless, to reduce time calculation it is suitable to approximate a convenient initial shape of chip by testing different shapes and dimensions before final calculation. The mesh in zone 2 was totally fixed in space according to an Eulerian description, where the material particle flows through the mesh as a fluid. This method allows to avoid the mesh distortion problem that represents the main drawback of the Lagrangian formulation.

2.1.1.4. Time integration method. In dynamic coupled thermomechanical problem such as metal cutting simulation, stresses are function of strain $(\varepsilon)$, strain rate $(\dot{\varepsilon})$ and temperature $(T)$. The interdependence and the variation of these parameters with time require calculating them simultaneously at each time increment where the use of explicit time integration is more suitable. In addition, explicit time integration is more efficient for analysis involving high nonlinearities. In explicit integration method, at each time increment, nodal acceleration has to be expressed in terms of displacements $\left(u^{(i)}\right)$, velocities $\left(\dot{u}^{(i)}\right)$ and accelerations $\left(\ddot{u}^{(i)}\right)$ at previous increment and calculated by resolving Eq. (6). The equations of body motion is integrated using the explicit 
central difference integration rule:

$\left\{\begin{array}{l}\dot{u}^{(i+1 / 2)}=\dot{u}^{(i-1 / 2)}+\frac{\Delta t^{(i+1)}+\Delta t^{(i)}}{2} \ddot{u}^{(i)} \\ u^{(i+1)}=u^{(i)}+\Delta t^{(i+1)} \dot{u}^{(i+1 / 2)}\end{array}\right.$

Mechanical non equilibrium is corrected for the global structure with implicit integration by simultaneously resolving of differential equations after formulation and inversion of the global structural matrix.

2.1.1.5. Contact and friction law. The most realistic description of normal and frictional stress distributions at tool-chip interface has been proposed by Zorev [29]. As shown in Fig. 4, the author assumes that the tool-chip interface is subdivided into two zones. In the first zone $(x \leq l p)$ the shear stress reaches the saturation values $\tau_{\text {Max }}$ and sticking occurs. In the second zone $(l p<x \leq l c)$, the frictional shear stress does not reach the saturation values $\tau_{\text {Max }}$ and sliding occurs.

According to Zorev's description, the frictional stress can be expressed as follow:

$\left\{\begin{array}{l}\tau_{f}=\mu \times \sigma_{n} \text { if } \mu \times \sigma_{n}<\tau_{\operatorname{Max}} \text { (Sliding) } \\ \tau_{f}=\tau_{\operatorname{Max}} \text { if } \mu \times \sigma_{n} \geq \tau_{\operatorname{Max}} \text { (Sticking) }\end{array}\right.$

The friction coefficient $(\mu)$ is calculated from rake angle value $(\gamma)$ and measured force components extracted from experimental

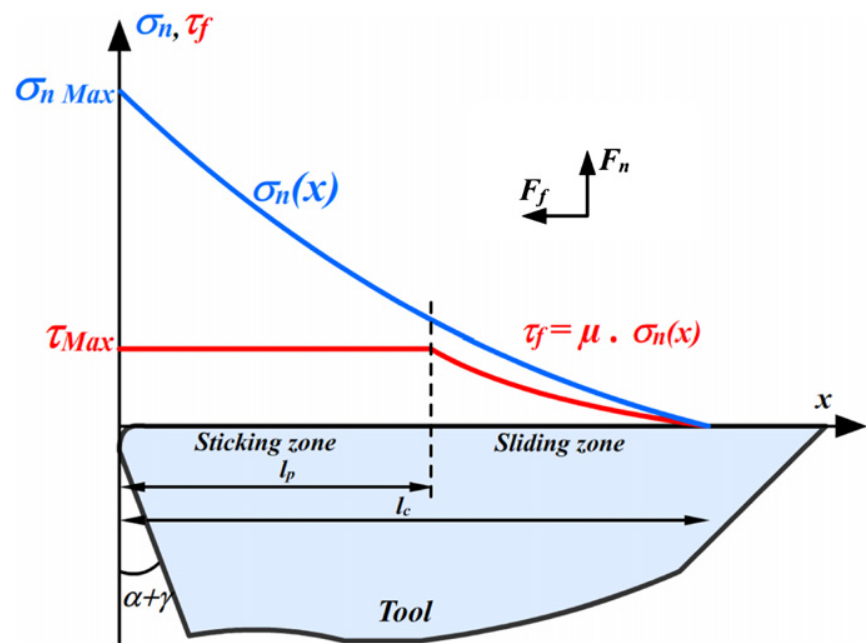

Fig. 4. Normal and frictional stress distributions at tool-chip interface [25]. results, presented in Table 5, by the relation:

$\mu=\frac{F_{t}+F_{c} \tan \gamma}{F_{c}-F_{t} \tan \gamma}$

Fig. 5 shows a high dependence of strain and temperature distribution in machined subsurface layers on frictional shear stress limit value $\left(\tau_{M a x}\right)$. This can be explained by variation of the tool/chip contact area according to $\tau_{\text {Max }}$ value.

The value of frictional shear stress limit was obtained by carrying out several simulations where the latter was varied until having a good agreement between the measured and calculated residual stresses and strains for machining conditions $2,3,6,7$ and 9 (Fig. 2).

The value of frictional stress limit $\left(\tau_{\operatorname{Max}}\right)$ was expressed as function of the cutting parameters by a polynomial function (Eq. $(9)$ ), where $(V c)$ is the cutting speed and $(D o c)$ is the depth of cut.

$$
\begin{aligned}
\tau_{M a x}= & -3.49(V c)+0.027(V c)^{2}-11408.5(D o c) \\
& +23828.5(D o c)^{2}+1607.5
\end{aligned}
$$

It is important to notice that this expression is useful within the ranges of variation of the cutting speed (60 to $140 \mathrm{~m} / \mathrm{min}$ ) and depth of cut ( 0.2 to $0.3 \mathrm{~mm}$ ) as indicated in Table 5 . These ranges are recommended by the cutting insert manufacture (Sandvik) for stainless steels.

In this work thermal conductance coefficient $\left(h_{1}\right)$ of 1000 $\mathrm{kW} / \mathrm{m}^{2} \mathrm{~K}$ was used to characterize the heat transfer at the toolchip and tool-workpiece interfaces. Filice et al. [24] show that this value allows to reach the stationary regime of temperature quickly so that good agreement between the simulated and measured profiles of residual stresses can be obtained.

2.1.1.6. Heat generation in orthogonal metal cutting. In machining, the temperature increases in cutting zone results from material plastic deformation and friction at tool-workpiece interface.

The local temperature increase induced by plastic work $\left(\Delta T_{p}\right)$ and friction $\left(\Delta T_{f}\right)$ in a time interval $(\Delta t)$, is calculated using Eqs. (10) and (11), respectively, where $\eta_{p}$ is the fraction of plastic deformation energy converted to heat, $\sigma$ the material flow stress, $\dot{\varepsilon}_{p}$ the plastic strain rate tensor, $J$ the equivalent heat conversion factor, $\rho$ the density, $C_{p}$ the specific heat capacity $\tau$, the shear stress at contact point and $\dot{S}$ the slip velocity.

$$
\frac{\Delta T_{p}}{\Delta t}=\eta_{p} \frac{\sigma \dot{\varepsilon}_{p}}{J C_{p} \rho}
$$

$\frac{\Delta T_{f}}{\Delta t}=\eta_{f} \frac{\tau \dot{S}}{J C_{p} \rho}$
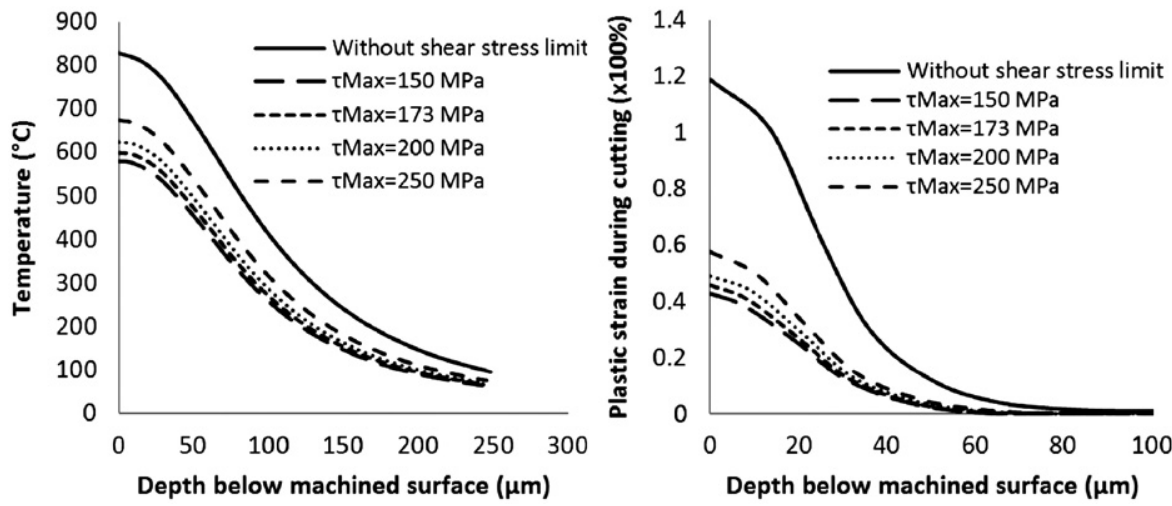

Fig. 5. Effects of frictional shear stress limit on simulation results. 
The fraction of frictional heat transferred to workpiece $(\beta)$ is function of tool and workpiece effusivities (Ef) and obtained by Eq. (12), where $(\lambda)$ is the thermal conductivity.

$\beta=\frac{E f_{w p}}{E f_{w p}+E f_{t}} \quad$ where $\quad E f=\left(\lambda \times \rho \times C_{p}\right)^{0.5}$

The temperatures are calculated by resolving the heat equation Eq. (13), where $(\pi)$ is the voluminal heat quantity and $\left(R_{p l}\right)$ defines the thermal internal source coming from mechanical contribution.

$\rho C_{p} \dot{T}-\lambda \Delta T=\pi+R_{p l}$

2.1.2. Simulation of residual stress and strain after relaxation and cooling (model II)

After cutting simulation, an implicit Lagrangian model was used to predict the induced residual stress and plastic strain. At this step the workpiece finds its mechanical balance and thermal cooling until the room temperature $\left(25^{\circ} \mathrm{C}\right)$. The modifications induced in workpiece subsurface during tool/material interaction in model I (stresses, strains and temperatures) are introduced in model II as initial conditions as shown in Fig. 1. In this model, the number of elements is reduced by deleting the tool and the chip. The heat transfer between the part and the ambient air is controlled by air convection factor $h_{2}=10 \mathrm{~kW} / \mathrm{m}^{2} \mathrm{~K}$.

\subsubsection{Numerical simulation results}

Using the above mentioned procedure, the stress, strain and temperature distributions during cutting (model I) and after cooling (model II) were calculated for several cutting conditions. Simulation results for cutting condition $(V c=140 \mathrm{~m} / \mathrm{min}$ and $D o c=0.25 \mathrm{~mm})$ are shown in Fig. 6((a)-(e)). It can be seen from Fig. 6(a) that the maximum Von Mises equivalent stress is located in the primary shear zone. A lower stress value of about $1170 \mathrm{MPa}$ is obtained in the new generated surface. After unloading and cooling, the surface stress decreases to $827 \mathrm{MPa}$ in cutting direction and $542 \mathrm{MPa}$ in axial direction (Fig. 6((d) and (e)).

Fig. 6(a) shows a high level of strain in secondary shear zone. This can be explained by a high thermal softening caused by excessive heating in this zone as shown in Fig. 6(c). A slighter value of strain is obtained in new generated surface and its value decreases, after unloading and cooling, to about 66\% (Fig. 6(f)).

These results are validated by experimental data provided in this study, involving residual stress and plastic strain measurements.

\section{Validation procedure}

\subsection{Experimental setup}

An experimental investigation is proposed in this work to assess the predictive capability of the numerical approach. Cutting tests have been carried out by turning of AISI 316L disks of $50 \mathrm{~mm}$ diameter and $5 \mathrm{~mm}$ thickness, under orthogonal cutting configuration (Fig. 7).

Nine cutting experiments using different cutting conditions (Table 5) have been conducted. Five of them have been used to calibrate the frictional shear stress limit given by Eq. (9) (conditions 2, 3, 6, 7 and 9) and four others (conditions 1, 4, 5 and 8) have been used to validate the numerical simulation results. For all machining conditions the feed rates are chosen equal to the depths of cut to avoid the effects of sequential cuts. A CVD TiCN$\mathrm{Al}_{2} \mathrm{O}_{3}$-TiN coated carbide insert with a rake angle $\gamma$ of $0^{\circ}$, a clearance angle $\alpha$ of $7^{\circ}$ and a cutting edge radius $R_{n}$ of $20 \mu \mathrm{m}$ is used for the experiments. The turning tests were carried out on a numerical controlled lathe (RealMeca T400), equipped with a piezo-electric transducer-based type dynamometer (type Kistler 9257B). The cutting and feed forces for all test conditions are listed in Table 5. The recorded values of cutting and thrust forces have been used to determine friction coefficient used in numerical model as explained previously.
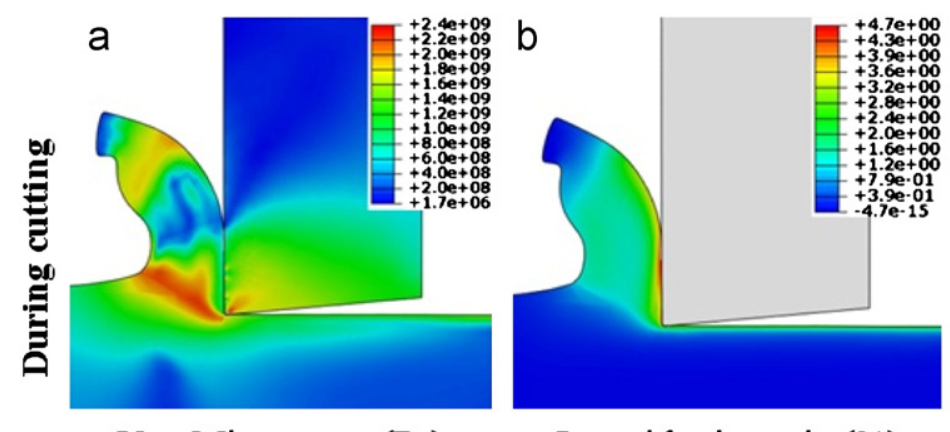

Logarithmic strain (\%)

e

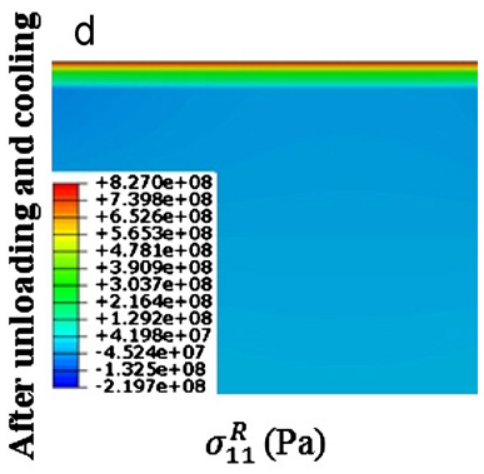

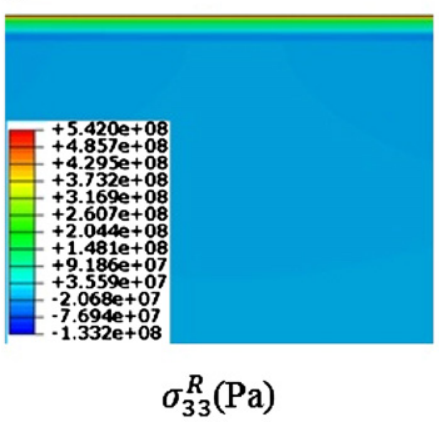

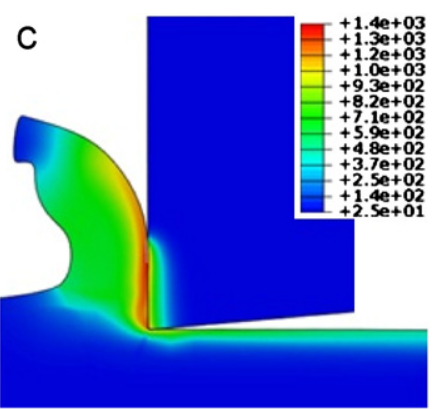

Temperature $\left({ }^{\circ} \mathrm{K}\right)$
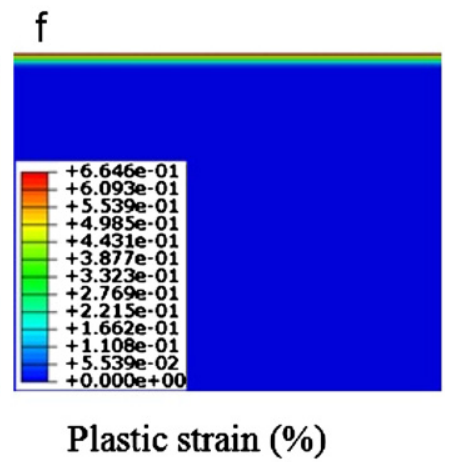

Fig. 6. Simulation results for condition $1(V c=140 \mathrm{~m} / \mathrm{min}, D o c=0.25 \mathrm{~mm})$. 

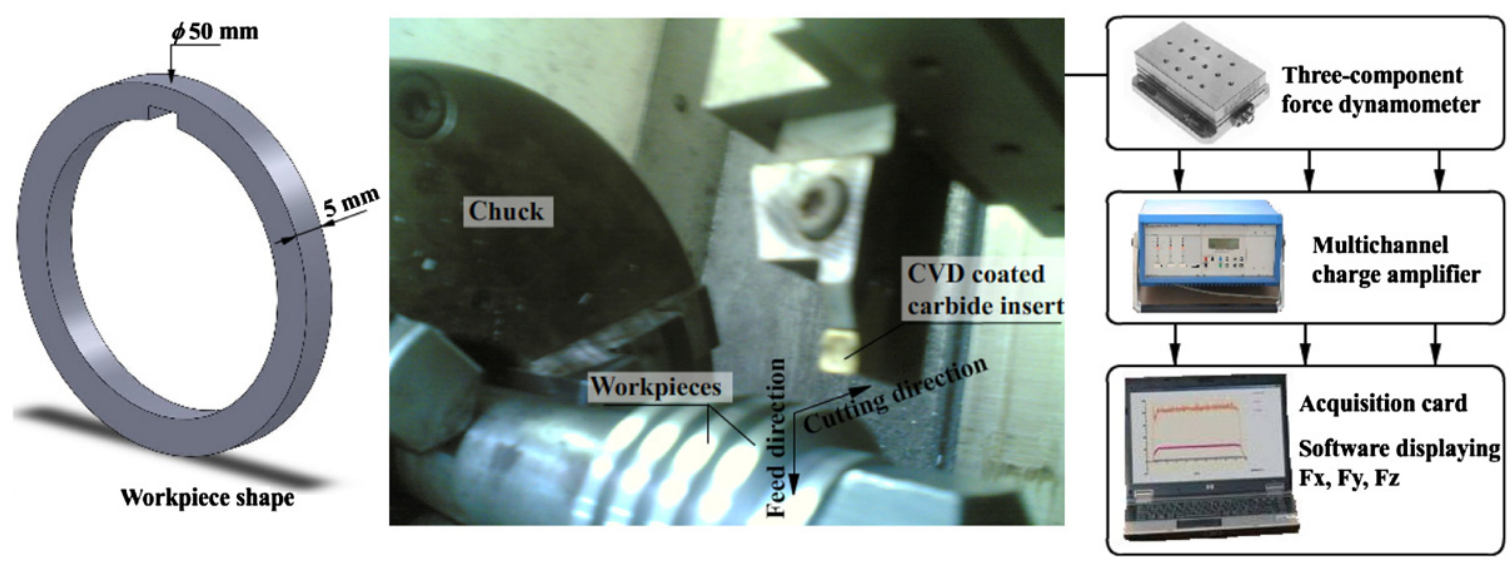

Fig. 7. Experimental setup used for orthogonal turning and cutting force measurement.

Table 6

Experimental results.

\begin{tabular}{|c|c|c|c|c|c|c|}
\hline \multicolumn{4}{|c|}{ Machining conditions } & \multirow{2}{*}{\multicolumn{3}{|c|}{$\begin{array}{l}\text { Machined surface properties } \\
\text { Residual stresses (MPa) }\end{array}$}} \\
\hline \multirow[t]{2}{*}{$\mathrm{N}^{\circ}$} & \multirow[t]{2}{*}{$V c(\mathrm{~m} / \mathrm{min})$} & \multirow[t]{2}{*}{$\operatorname{Doc}(\mathrm{mm})$} & \multirow[t]{2}{*}{ Microhardness (HV) } & & & \\
\hline & & & & $\sigma_{11(\operatorname{Max})}^{R}$ & $\sigma_{33(\operatorname{Max})}^{R}$ & $\operatorname{ALT}(\mu \mathrm{m})$ \\
\hline 1 & 140 & 0.25 & 460 & $827 \pm 266$ & $542 \pm 62$ & 130 \\
\hline 2 & 100 & 0.25 & 352 & $989 \pm 44$ & $664 \pm 48$ & 117 \\
\hline 3 & 60 & 0.25 & 335 & $650 \pm 114$ & $570 \pm 62$ & 145 \\
\hline 4 & 140 & 0.2 & 480 & $756 \pm 107$ & $426 \pm 70$ & 135 \\
\hline 5 & 100 & 0.2 & 370 & $861 \pm 29$ & $728 \pm 72$ & 114 \\
\hline 6 & 60 & 0.2 & 360 & $590 \pm 68$ & $435 \pm 60$ & 140 \\
\hline 7 & 140 & 0.3 & 500 & $1049 \pm 125$ & $897 \pm 66$ & 132 \\
\hline 8 & 100 & 0.3 & 420 & $1302 \pm 50$ & $1076 \pm 93$ & 120 \\
\hline 9 & 60 & 0.3 & 390 & $815 \pm 104$ & $662 \pm 60$ & 150 \\
\hline
\end{tabular}

Table 7

X-ray diffraction conditions.

\begin{tabular}{ll}
\hline Radiation & $\begin{array}{l}\text { Mn } K_{\alpha} \\
\lambda=0.209 \mathrm{~nm}\end{array}$ \\
\hline $\begin{array}{ll}\text { Voltage } \\
\text { Current }\end{array}$ & $20 \mathrm{kV}$ \\
$\begin{array}{l}\text { X-ray diffraction } \\
\text { planes }\end{array}$ & $2 \theta=152^{\circ}$ \\
Beam diameter & $2 \mathrm{~mm}$ \\
$\phi$ angles & $0^{\circ}$ and $90^{\circ}$ \\
$\psi$ oscillation & $\pm 3^{\circ}$ \\
Number of $\psi$ angles & 17 \\
\hline
\end{tabular}

\subsection{Identification of the machined surface properties}

\subsubsection{Microhardness tests}

A Shimadzu HMV2000 micro-hardness tester is used to quantify the cold work hardening by measuring the variation of microhardness generated by machining for each cutting condition. The applied force and duration of indentation are $50 \mathrm{gf}$ and $15 \mathrm{~s}$, respectively. The obtained surface microhardness levels for the different cutting conditions are listed in Table 6.

\subsubsection{X-ray diffraction}

Residual stress profiles were evaluated by the $\psi$ tilt X-ray method using a SET-X-type diffractometer (manufactured by Elphyse France) under the conditions listed in Table 7. The indepth residual stresses were measured after performing an

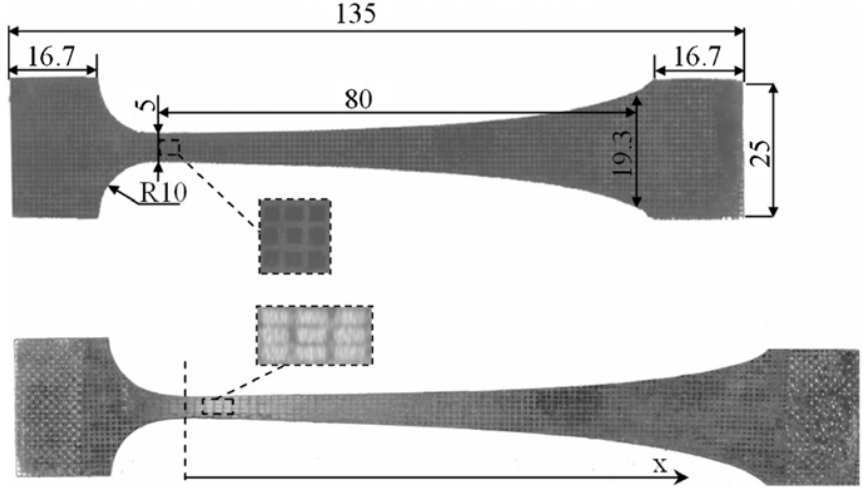

Fig. 8. Shape and dimensions of specific tensile sample before and after tensile test.

incremental electrochemical etching. Near surface residual stresses and affected layer thickness for different cutting condition are listed in Table 6.

\subsubsection{Relationship between microhardness and plastic strain}

In order to establish a relationship between the micro-hardness and the equivalent plastic strain, a tensile test was carried out on a specific tensile sample. The shape of the specific tensile sample offers different levels of plastic strain values along the calibrated area (Fig. 8). Micro hardness measured along the tensile sample can be plotted as function of equivalent plastic strain. 
To find out the shape and dimension of tensile sample, the law of evolution of the useful section during the tensile test was established. In this step, the material behavior was described by the relation:

$\sigma_{y}=A+B\left(\varepsilon_{e q}^{p}\right)^{n}$

By selecting a coefficient $\mathbf{K}$ controlling the plastic strain evolution along the useful zone equal to 0.016 , the shape and dimension of tensile sample were totally determined. The sample was obtained by wire EDM from the same bar used for cutting tests and electro polished by layers of $50 \mu \mathrm{m}$ until reaching a homogeneous micro-hardness of $192 \mathrm{HV}$. A grid made up of squares $(1 \times 1 \mathrm{~mm})$ was electro graved on the tensile sample (Fig. 8).

The grid's dimensions before and after tensile test were observed by optical microscope and used to calculate the equivalent plastic strain evolution in calibrated area (Fig. 9(a)). After tensile test, the evolution of microhardness along the sample was measured (Fig. 9(b)). The level of microhardness at each point was performed by averaging five measurements. Thereafter, the curve expressing the evolution of the micro-hardness according to the equivalent plastic strain was established (Fig. 10). This curve will be used to validate the plastic strain calculated by numerical simulation.

\subsubsection{Validation}

In order to verify the capability of the proposed numerical approach to predict the properties of layers affected by machining, the residual stress and plastic strain calculated by the finite element model were compared to experimental results. Fig. 11 illustrates the predicted and measured residual stress profiles for the same cutting conditions. The plastic strains calculated by numerical model are compared to those deduced from microhardness-plastic strain relationship as explained previously (Fig. 12). The simulation results show good agreement between calculated and measured residual stresses and plastic strains proving the satisfactory capability of the suggested procedure to predict the gradients of properties induced by machining.

\section{Effects of cutting conditions on the near surface properties}

The numerical simulation approach described and validated in this study will be used to establish the effect of cutting conditions on AISI 316L surface gradient properties. This study is based on the analysis of simulated profiles of residual stress and plastic strain resulting from nine cutting conditions (Figs. 13 and 16).

\subsection{Residual stresses}

The residual stress distributions plotted in Fig. 13 show that both circumferential and axial residual stresses are tensile in the near surface layers with higher value in the outer layer. The maximum calculated residual stress value varies from 600 to $1290 \mathrm{MPa}$ and it is much higher than the bulk material yield stress (300 MPa). The residual stresses in cutting direction are higher than those in axial direction. It can be seen that the cutting speed and the depth of cut have a significant influence on the near surface residual stresses and on the affected layers thickness.

\subsubsection{Effect of cutting speed}

There are two residual stress evolution tendencies with increasing the cutting speed for each depth of cut (Fig. 14):

For low cutting speed $(V c<100 \mathrm{~m} / \mathrm{min})$, tensile surface residual stresses increase significantly in both directions with increasing of the cutting speed.

For high cutting speed $(V c>100 \mathrm{~m} / \mathrm{min})$, tensile surface residual stresses decrease in both directions with increasing the cutting speed.

This result can be explained by the contribution of thermal effect in the machining residual stress generation process (Fig. 15). Two competitive phenomena are thought to occur at the cutting zone: an increase of generated heat in cutting zone $(\mathbf{Q})$ with increasing cutting speed which is counterbalanced by a decrease of transferred heat fraction to workpiece $\left(\mathbf{Q}_{\mathbf{w}}\right)$. In fact, two sources of heat are assumed to generate the temperature rise in the machined part during cutting: plastic deformations in shear zones and friction between the tool and the workpiece (Fig. 15). The created heat is transferred to chip $\left(\mathbf{Q}_{\mathbf{C}}\right)$, to tool $\left(\mathbf{Q}_{\mathbf{T}}\right)$ and to workpiece $\left(\mathbf{Q}_{\mathbf{w}}\right)$ in proportions depending on tool and material properties and cutting conditions. For a range of cutting speed lower than a value of $100 \mathrm{~m} / \mathrm{min}$, the material removal rate $\dot{Z}$ is low and leads to a weak rate of thermal dissipation by the chip $\left(\dot{Q}_{C}\right)$. A higher quantity of heat is then transmitted to the workpiece surface $\left(\mathbf{Q}_{\mathbf{w}}\right)$ causing an increase of tensile residual stress

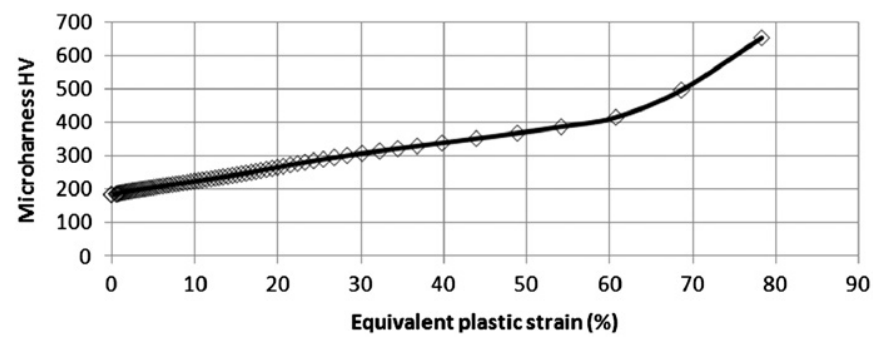

Fig. 10. Microhardness/plastic strain correspondence of the AISI 316L stainless steel.
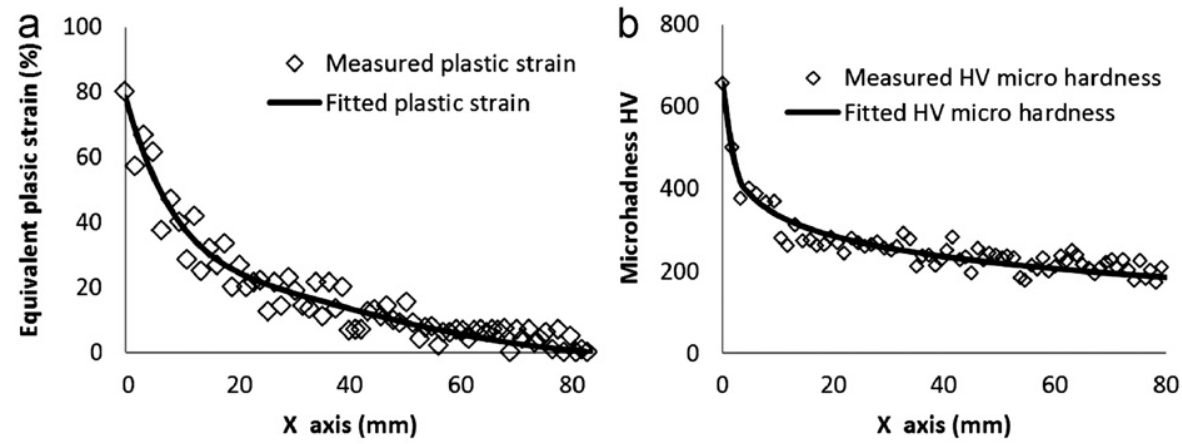

Fig. 9. Evolution along tensile sample of: (a) equivalent plastic strain, (b) microhardness. 

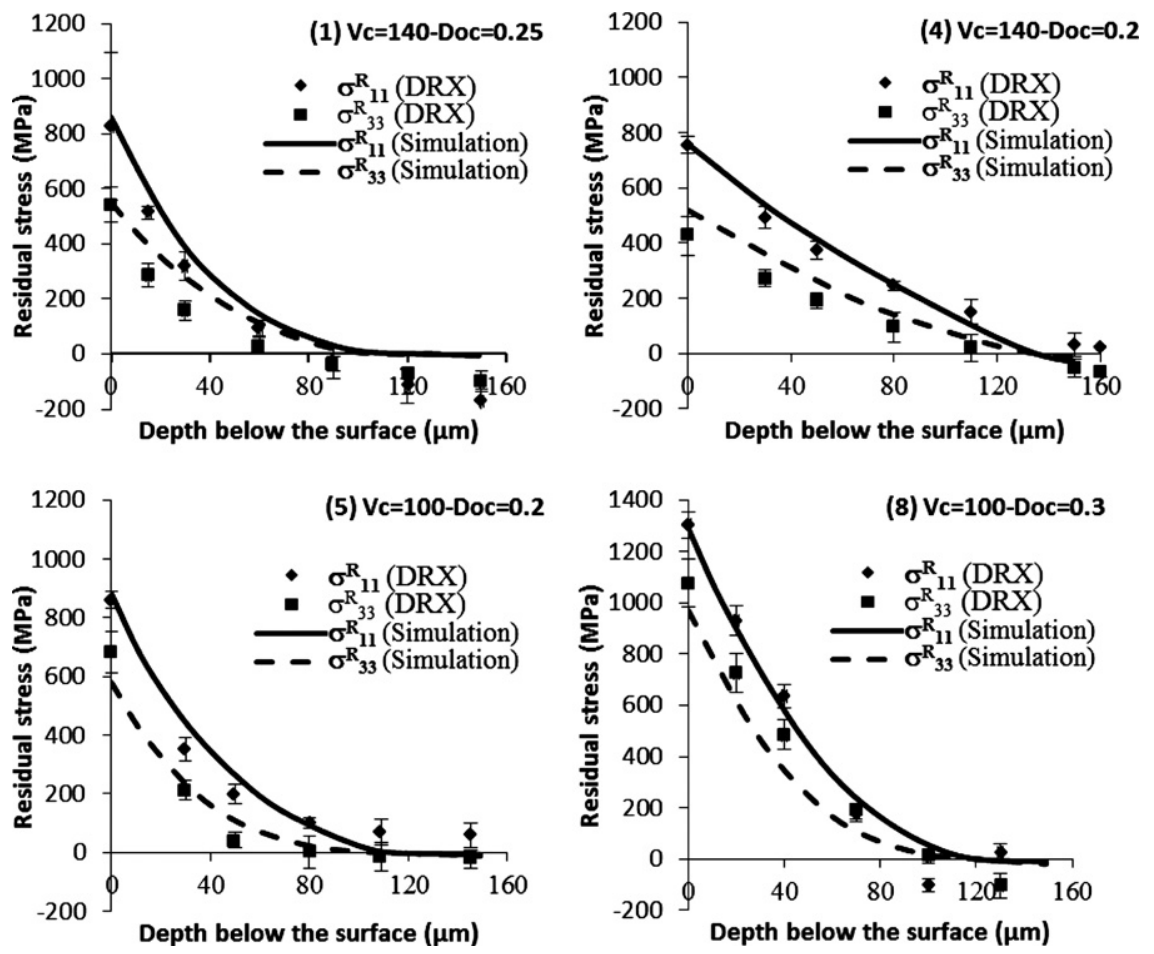

Fig. 11. Measured and simulated residual stresses comparison.
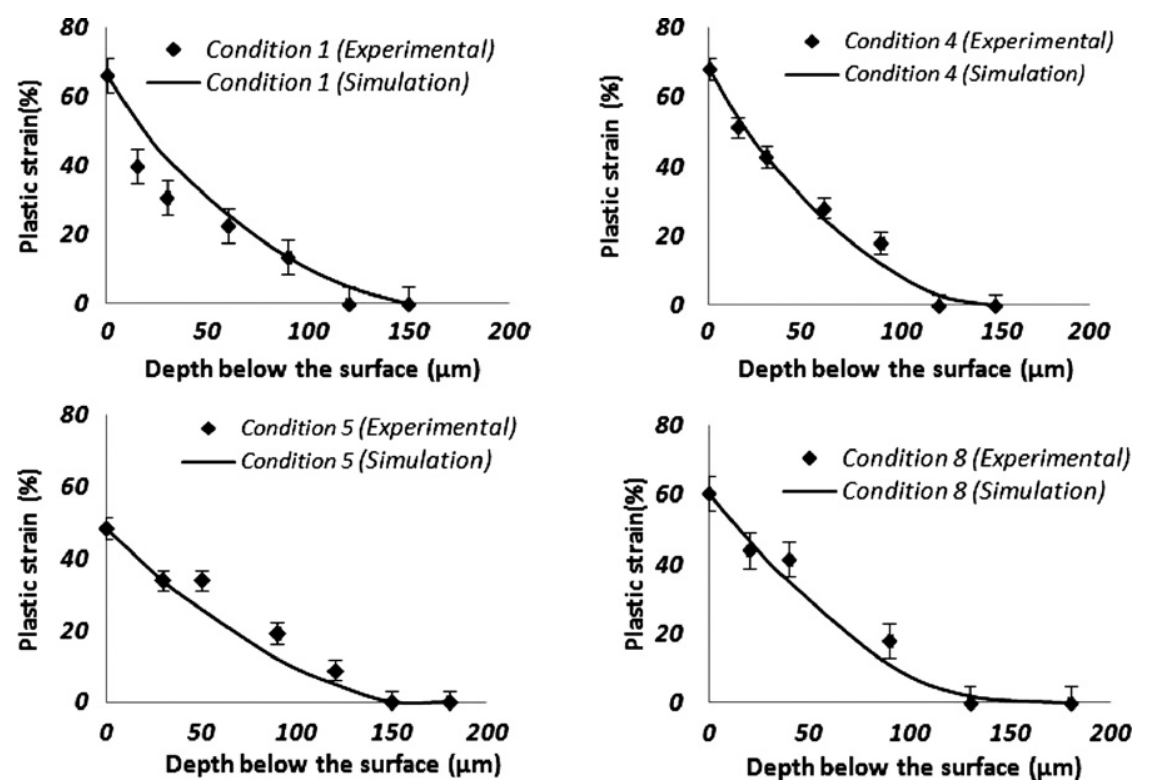

Fig. 12. Measured and simulated plastic strain comparison.

(Fig. 14). For higher speeds, the material removal rate $\dot{Z}$ raises and the chip as well as the quantity of associated heat $\left(\mathbf{Q}_{\mathbf{c}}\right)$ remains in the cutting zone for shorter time. Therefore, the rate of heat dissipation in the machined surface $\left(\dot{Q}_{W}\right)$ decreases (Fig. 14). This leads to a decrease of the tensile residual stress. The same residual stress evolution tendency depending on the cutting speed was observed by Pawade et al. [30] when nickel alloy was machined. These authors found that the maximum residual stress was reached at a cutting speed of $300 \mathrm{~m} / \mathrm{min}$. This was explained by the quantity of heat dissipation that determines the nature of deformation for materials with poor thermal conductivity.

\subsubsection{Effect of depth of cut}

The numerical simulation results show an increase in tensile surface residual stress in both directions when depth of cut increases from 0.2 to $0.3 \mathrm{~mm}$ (Fig. 14). This result can be explained by the contribution of the thermal effects resulting from an increase of cutting zone size and the heat created by 

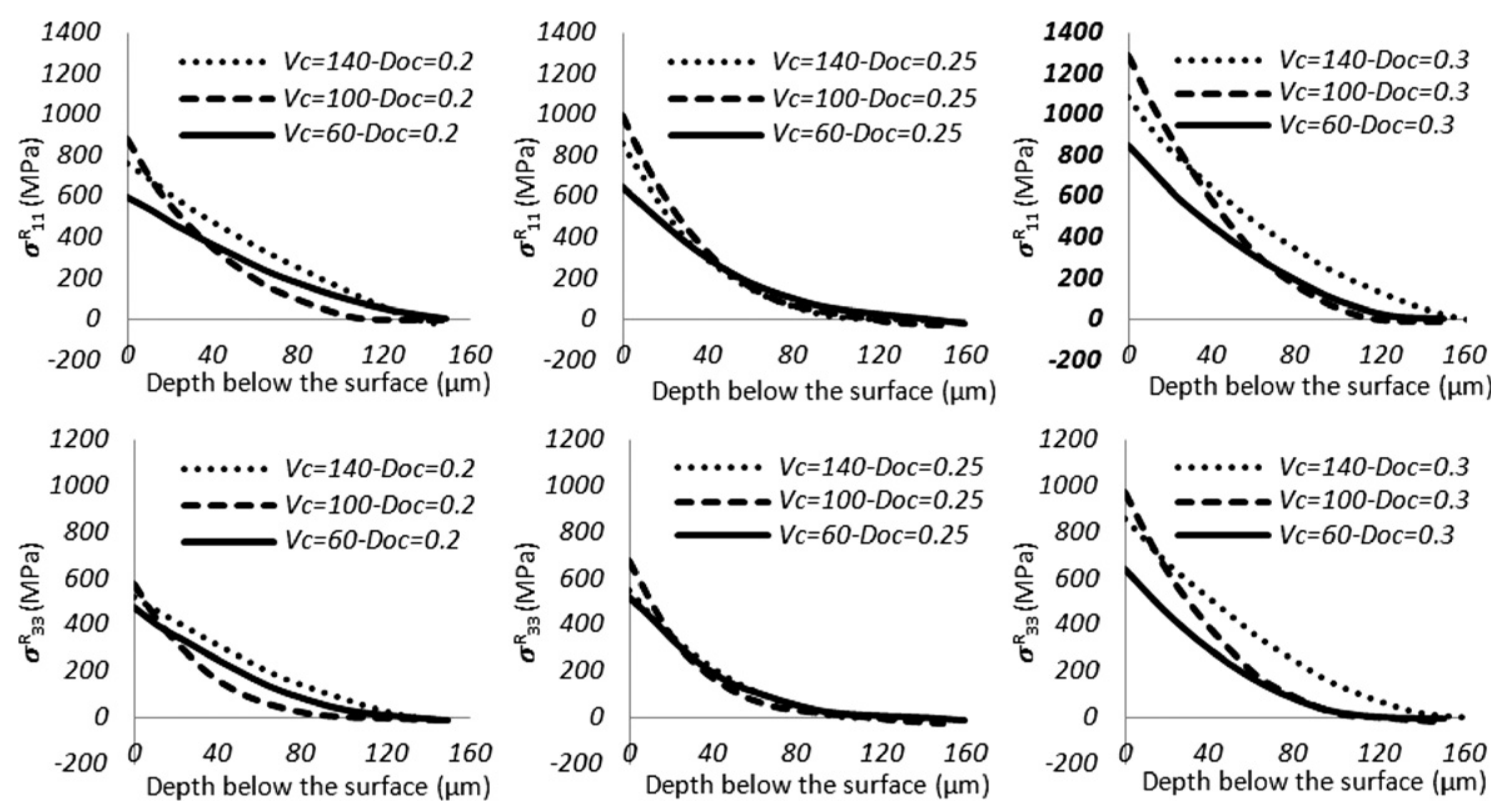

Fig. 13. Effect of cutting conditions on residual stresses.
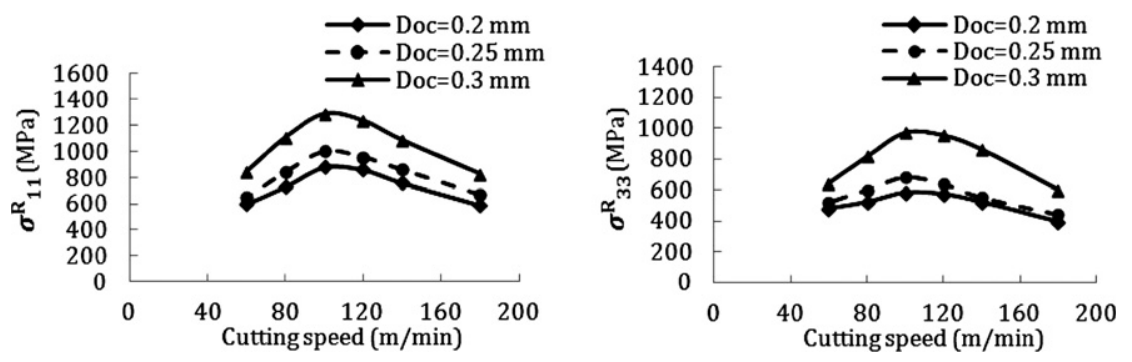

Fig. 14. Effect of cutting conditions on near surface residual stresses.
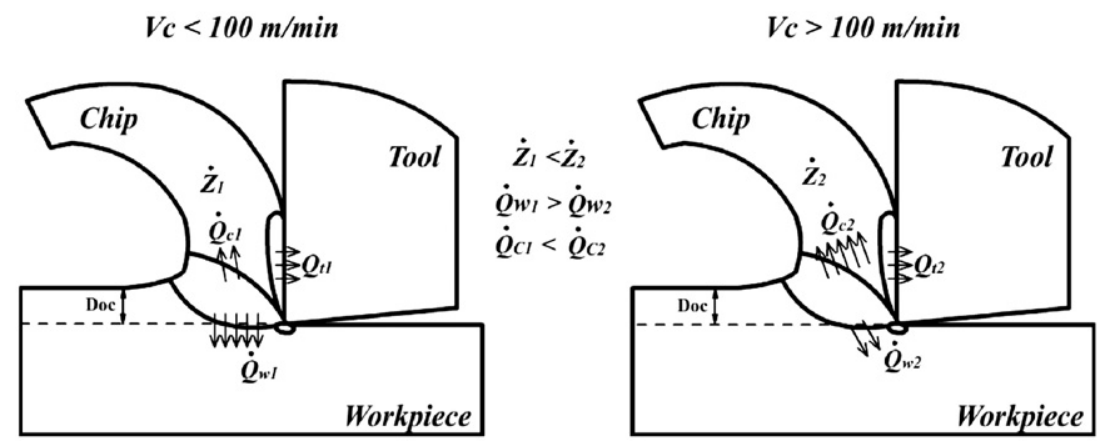

Fig. 15. Effect of cutting speed on thermal load during cutting.

friction and plastic deformation when the depth of cut becomes higher. This result is in good agreement with the result found by Outeiro et al. [8] and by Mohammadpour et al. [9] by numerical simulation of residual stress induced by machining of AISI316L and AISI1045, respectively.

\subsection{Plastic strain}

\subsubsection{Effect of cutting speed}

In the current work, the cold work hardening induced in machined surface layers is quantified in term of plastic strain that can be converted to microhardness as explained previously. For all cutting conditions, a work hardening takes place at the machined subsurface layers until a depth of around $150 \mu \mathrm{m}$ with higher levels in the outer layers (Fig. 16). The cross section optical micrograph reveals a deformed structure resulting from machining characterized by slip lines localized in the stretched grains (Fig. 17).

As shown in Fig. 18, a rise of subsurface plastic strain was obtained for higher cutting speeds. In fact, an increase of plastic strain of about $24 \%$ was obtained, for a depth of cut of $0.25 \mathrm{~mm}$, when cutting speed increases from 60 to $140 \mathrm{~m} / \mathrm{min}$. This increase is accompanied by a drop of affected layer thickness of about $55 \mu \mathrm{m}$. It can be seen from Fig. 18, that the effect of cutting speed on plastic strain in the machined surface is more important 

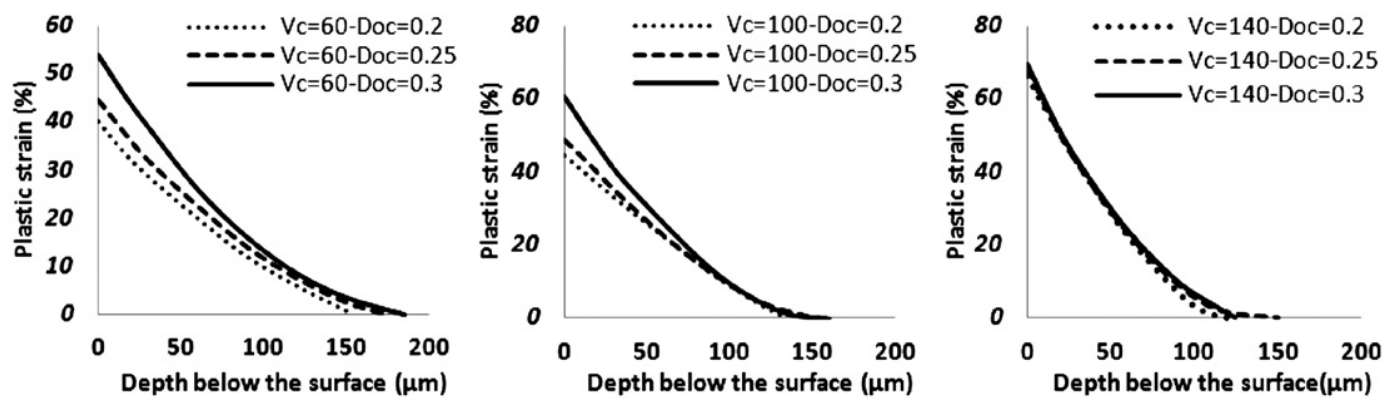

Fig. 16. Effect of cutting conditions on the residual strain distribution.

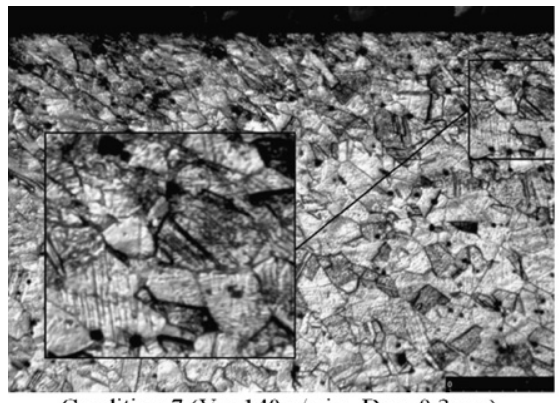

Condition $7(\mathrm{Vc}=140 \mathrm{~m} / \mathrm{min}, \mathrm{Doc}=0.3 \mathrm{~mm})$

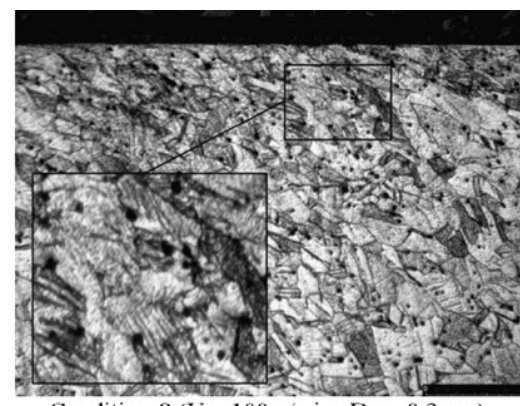

Condition $8(\mathrm{Vc}=100 \mathrm{~m} / \mathrm{min}, \mathrm{Doc}=0.3 \mathrm{~mm})$

Fig. 17. Deformed structure of machined surface layers.
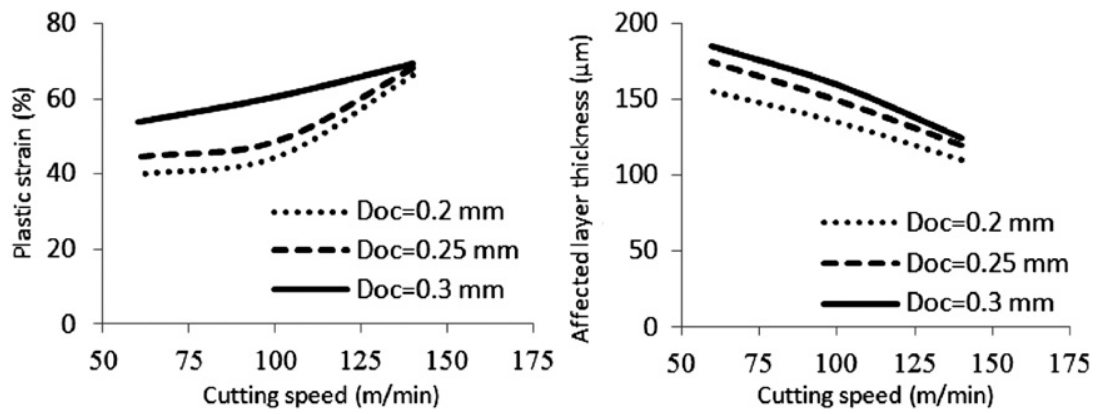

Fig. 18. Effect of cutting conditions on maximal plastic strain and hardened layer thickness.

for lower levels of depth of cut. For higher cutting speed level $(140 \mathrm{~m} / \mathrm{min})$, the plastic strain seems to depend slightly on depth of cut and it stabilizes at a value of around 68\%. The affected layer thickness decreases gradually with a further increase of cutting speed and tends to stabilize at a value of around $120 \mu \mathrm{m}$.

\subsubsection{Effect of depth of cut}

The cold work induced to machined surface layers is less sensitive to the depth of cut. Nevertheless, the cold work has a tendency to increase for higher level of depths of cut (Fig. 18). This result can be explained by material softening caused by high thermal load when depth of cut increases.

\section{Conclusions}

In this study a numerical approach was developed using an ALE approach to predict machining induced residual stresses and plastic strain in orthogonal cutting. A set of experimental results was used to calibrate the frictional shear stress limit and the simulated plastic strain gradient has been validated by a microhardness-strain relationship established experimentally in this study. This relationship is based on the use of a specifically designed tensile sample that offers different levels of cold work hardening values along the calibrated area after tensile test.

The simulated machining residual stresses are experimentally validated by X-ray diffraction under different cutting conditions and supported by an assessment of plastic strain which is the basis of their generation.

The proposed method is suitable to investigate the effects of process parameters on cold work hardening in the machined affected layer.

The good agreement between experimental and numerical results proves the efficiency of the proposed procedure to investigate the influence of cutting parameters on the gradient of properties of machined surface. The model has been applied to predict the residual stress and plastic strain induced by machining the AISI 316L with different levels of cutting speed and depth of cut. Numerical results show that a reduction of tensile stress level in machined subsurface was obtained when a high cutting 
speed and a low depth of cut are used. This result was confirmed by experimental investigations. The proposed methodology can be extended for other materials and cutting processes.

\section{References}

[1] Ben Fathallah $B$, Ben Fredj $N$, Sidhom $H$, Braham $C$, Ichida $Y$. Effects of abrasive type cooling mode and peripheral grinding wheel speed on the AISI D2 steel ground surface integrity. Int J Mach Tools Manuf 2009;49:261-72.

[2] Molinari A, Moufki A. The merchant's model of orthogonal cutting revisited: a new insight into the modeling of chip formation. Int $\mathrm{J}$ Mech Sci 2008;50:124-31.

[3] Issa MM, Saanouni K, Labergère C, Rassineux A. Prediction of serrated chip formation in orthogonal metal cutting by advanced adaptive 2D numerical methodology. Int J Mach Mater 2011;9:295-315.

[4] Saanouni K, Lestriez P, Labergere C. 2D adaptive FE simulations in finite thermo-elasto-viscoplasticity with ductile damage: application to orthogonal metal cutting by chip formation and breaking. Int J Damage Mech $2011 ; 20: 23-61$

[5] Lin ZC, Ship PL. A study of deformation of the machined workpiece and tool under different low cutting velocities with an elastic cutting tool. Int J Mech Sci 1998;40 663-661.

[6] Lin ZC, Lai WL, Liu CR. The study of ultra-precision machining and residual stress for NiP alloy with different cutting speeds and depth of cut. J Mater Process Technol 2000;97:200-10.

[7] Lin ZC, Lin YY. A study of oblique cutting for different low cutting speeds. J Mater Process Technol 2001;115:313-25.

[8] Outeiro JC, Umbrello D, M'Saoubi R. Experimental and numerical modeling of the residual stresses induced in orthogonal cutting of AISI 316L steel. Int $\mathrm{J}$ Mach Tools Manuf 2006;46:1786-94.

[9] Mohammadpour M, Razfar MR, Saffar RJ. Numerical investigating the effect of machining parameters on residual stresses in orthogonal cutting. Simul Modell Pract Theory 2010;18:378-89.

[10] Balkrishna R, Chinmaya RD, Yung CS. An experimental and numerical study on the face milling of Ti-6Al-4V alloy: tool performance and surface integrity. J Mater Process Technol 2011;211:294-304.

[11] Guo YB, Liu CR. Residual stress formation mechanism and its control by sequential cuts. Trans NAMRI/SME 2000;28:179-84.

[12] Salio M, Berruti T, De Poli G. Prediction of residual stress distribution after turning in turbine disks. Int J Mech Sci 2006;48:976-84.

[13] Liu CR, Guo YB. Finite element analysis of the effect of sequential cuts and tool-chip friction on residual stresses in a machined layer. Int J Mech Sci 2000;42:1069-86.

[14] Ee KC, Dillon OW, Jawahir IS. Finite element modeling of residual stresses in machining induced by cutting using a tool with finite edge radius. Int J Mech Sci 2005;47:1611-28.
[15] Shih AJ. Finite element analysis of the rake angle effects in orthogonal metal cutting. Int J Mech Sci 1996;38:1-17.

[16] Ship PL. An analysis of cutting under different rake angles using the finite element method. J Mater Process Technol 2000;105:143-51.

[17] Shet C, Deng X. Residual stresses and strains in orthogonal metal cutting. Int J Mach Tools Manuf 2003;43:573-87.

[18] Hua J, Umbrello D, Shivpuri R. Investigation of cutting conditions and cutting edge preparations for enhanced compressive subsurface residual stress in the hard turning of bearing steel. J Mater Process Technol 2006;171:180-7.

[19] Outeiro JC, Pina JC, M'Saoubi R, Pusavec F, Jawahir IS. Analysis of residual stresses induced by dry turning of difficult-to-machine materials. CIRP Ann-Manuf Technol 2008;57:77-80.

[20] Maranhao C, Davim JP. Finite element modelling of machining of AISI 316 steel: numerical simulation and experimental validation. Simul Modell Pract Theory 2010;18:139-56.

[21] Nasr MNA, Ng E-G, Elbestawi MA. Modelling the effects of tool-edge radius on residual stresses when orthogonal cutting AISI 316L. Int J Mach Tools Manuf 2007;47:401-11.

[22] Munoz-Sanchez A, Canteli JA, Cantero JL, Miguelez MH. Numerical analysis of the tool wear effect in the machining induced residual stresses. Simul Modell Pract Theory 2011;19:872-86.

[23] Umbrello D, M'Saoubi R, Outeiro JC. The influence of Johnson-Cook material constants on finite element simulation of machining of AISI 316L steel. Int J Mach Tools Manuf 2007;47:462-70.

[24] Filice L, Micari F, Rizzuti S, Umbrello D. A critical analysis on the friction modelling in orthogonal machining. Int J Mach Tools Manuf 2006;174: 286-92.

[25] Huang J, Shivpuri R, Cheng X, Bedekar V, Matsumoto Y, Hashimoto F, Watkins TR. Effect of feed rate, workpiece hardness and cutting edge on subsurface residual stress in the hard turning of bearing steel using chamfer + hone cutting edge geometry. Mater Sci Eng 2005;394:238-48.

[26] Johnson, GR, Cook, WH, A constitutive model and data for metals subjected to large strains, high strain rate, and temperatures, Proceedings of the seventh international symposium on Ballistics, The Hague, The Netherlands, 54 (1983) pp. 541-7.

[27] M'Saoubi R. Aspects Thermiques et Microstructuraux de la coupe. in, France: Application à la coupe orthogonale des aciers austénitiques; 1998.

[28] Donea J, Huerta A, Ponthot J-P, Rodriguez-Ferran A. Arbitrary LagrangianEulerian Methods 2004.

[29] Zorev NN. Inter-relationship between shear processes occurring along tool face and shear plane in metal cutting. International research in production engineering. New York: ASME; 1963 42-9.

[30] Pawade RS, Joshi SS, Brahmankar PK. Effect of machining parameters and cutting edge geometry on surface integrity of high-speed turned Inconel 718. Int J Mach Tools Manuf 2008;48:15-28.

[31] Yung-Chang Yen MS. Modelling of metal cutting and ball burnishing-prediction of tool wear and surface properties. in, University the Ohio State; 2004. 